\title{
Effect of Curing Poly(p-Phenylene Sulfide) on Thermal Properties and Crystalline Morphologies
}

\author{
Sungho Lee, Do-Hwan Kim, Jae-Ha Park, Min Park, Han-Ik Joh, Bon-Cheol Ku* \\ Carbon Convergence Materials Research Center, Institute of Advanced Composites Materials, Korea Institute of Science and \\ Technology, Wanju-gun, Republic of Korea \\ Email: ${ }^{*}$ cnt@kist.re.kr
}

Received January 10, 2013; revised February 10, 2013; accepted March 10, 2013

Copyright (C) 2013 Sungho Lee et al. This is an open access article distributed under the Creative Commons Attribution License, which permits unrestricted use, distribution, and reproduction in any medium, provided the original work is properly cited.

\begin{abstract}
Commercial poly(p-phenylene sulfide) (PPS) was thermally cured, which resulted in an increase of molecular weight due to cross-linking. Non-isothermal crystallization studies of samples cured for up to 7 days at $250^{\circ} \mathrm{C}$ showed a monotonous increase of crystallization temperature compared to pure PPS. However, a further increase of curing time decreased the crystallization temperature. The change in the half-crystallization time $\left(t_{1 / 2}\right)$ was similar to the crystallization temperature. Thus, the cross-linking of PPS affected crystallization behaviors significantly. To a certain extent, crosslinks acted as nucleation agents, but excessive cross-linking hindered the crystallization. Morphologies observed by polarized optical microscopy suggested that thermal curing for as little as 1 day contributed to the spherulitic structure having a smaller size, that was not observed with pure PPS.
\end{abstract}

Keywords: Poly( $p$-Phenylene Sulfide); Thermal Curing; Non-Isothermal Crystallization; Cross-Linking; Crystalline Morphologies

\section{Introduction}

High performance thermoplastics have been developed and commercialized to satisfy the increasing demand for polymeric materials with such properties as thermal stability, high strength and modulus, and chemical resistance. Poly ( $p$-phenylene sulfide) (PPS) is one of the high performance polymers, having outstanding properties compared to conventional thermoplastics such as polyethylene and polypropylene [1]. Since Philips Petroleum Company commercialized PPS in 1967, the synthesis, processing, and applications have evolved to produce various grades of products with diverse properties [2-5].

One of the interesting characteristics of PPS is curability, which means that PPS undergoes chemical reactions on exposure to an oxygen-containing atmosphere at high temperatures, leading to an increase of viscosity due to cross-linking [6]. The extent of the viscosity increase is dependent on the temperature and time of such an exposure [6]. The virgin PPS is a linear material of molecular weight of about $20,000-25,000 \mathrm{~g} / \mathrm{mol}$, which is too low to be used as a molding resin, Therefore, an increase of molecular weight was necessary, and curability has been considered the most important characteristic in

\footnotetext{
"Corresponding author.
}

that the moderate molecular weight of virgin PPS could be conveniently increased by a post curing process after polymerization [7]. Ma et al. reported the curing mechanism of PPS using various analytical techniques, such as FT-IR, solid-state ${ }^{13} \mathrm{C}-\mathrm{NMR}$, and rheometric measurements [8]. They concluded that the two most important reactions in the melt cure of PPS were cross-linking and chain extension and that the distribution of molecular weight became broader and shifted toward higher molecular weight with increasing cure time [8].

The change of the internal structure of PPS that results from the curing reactions inevitably causes a change in the crystallization behavior, which is closely related to the morphology developed during processing. In this paper, the effect of the curing of PPS on its thermal properties and crystalline morphologies was studied. A commercial PPS resin was thermally cured from 1 to 16 days at $250^{\circ} \mathrm{C}$. To investigate the change of molecular weight during curing, the intrinsic viscosities of as-received and cured PPS were measured. Non-isothermal crystallization kinetics were investigated by differential scanning calorimetry (DSC). Furthermore, polarized optical microscopy (POM) was used to observe the morphologies of pure and cured PPS. 


\section{Experimental}

\subsection{Materials}

PPS powders (W316 grade, density and molecular weight of $1.35 \mathrm{~g} / \mathrm{cm}^{3}$ and $35,000 \mathrm{~g} / \mathrm{mol}$, respectively) supplied by Kureha Chemical Industry Co., Ltd (Japan) were used for this study. The PPS powders were encased in a 20 $\mathrm{mL}$ vial and then the samples were cured at $250^{\circ} \mathrm{C}$ for 1 to 16 days in an air atmosphere.

\subsection{Characterization}

The intrinsic viscosities of pure and cured PPS were obtained using a Brookfield viscometer with a Thermosel system and a S18 spindle (DV-II + Pro, Brookfield Co., UK). Samples were dissolved in 1-chloro naphthalene for preparing $4 \mathrm{wt} \%$ polymer solutions at $210^{\circ} \mathrm{C}$. The intrinsic viscosities were calculated using the Solomon-Ciuta relation as follows [9]:

$$
[\eta]=\frac{\eta_{s p} / C}{1+k \eta_{s p}}
$$

where $k$ is 0.302 for PPS as a material property, $C$ is the concentration of polymer in 1-chloro naphthalene, $[\eta]$ is the intrinsic viscosity, and $\eta_{s p}$ is the specific viscosity. The viscosity-average molecular weight was calculated using the Mark-Houwink-Sakurada (MHS) equation as follows:

$$
[\eta]=K M_{V}^{a}
$$

where $K$ and a are $8.91 \times 10^{-5}$ and 0.747 for PPS, respectively [9].

Thermal analysis was performed in a differential scanning calorimeter (DSC Q20, TA Instruments, USA). Samples were heated up to $350^{\circ} \mathrm{C}$ at a rate of $10^{\circ} \mathrm{C} / \mathrm{min}$ and held at that temperature for $10 \mathrm{~min}$ to erase the thermal histories of the samples. Subsequently, samples were cooled down to $50^{\circ} \mathrm{C}$ at a rate of $10^{\circ} \mathrm{C} / \mathrm{min}$ and then heated up to $350^{\circ} \mathrm{C}$ again at a rate of $10^{\circ} \mathrm{C} / \mathrm{min}$ to study the effect of curing on the non-isothermal crystallization. The crystalline morphologies were examined in an Olympus BX-60 optical microscope (Olympus, Japan) with cross-polarizers. The samples were loaded on a hot stage (Mettler Toledo FP82HT, USA), and heated up to $350^{\circ} \mathrm{C}$ at a rate of $10^{\circ} \mathrm{C} / \mathrm{min}$. Samples were squeezed to be a thin film with holding at $350^{\circ} \mathrm{C}$ for $10 \mathrm{~min}$. Then, samples were cooled down to $50^{\circ} \mathrm{C}$ at a rate of $10^{\circ} \mathrm{C} / \mathrm{min}$, and the crystalline morphologies of the samples observed.

\section{Results and Discussion}

\subsection{Molecular Weight}

The intrinsic viscosities of as-received and thermally cured PPS at $250^{\circ} \mathrm{C}$ were obtained using the SolomonCiuta relation. Since samples cured for more than 7 days did not dissolve in 1-chloro naphthalene, intrinsic viscosities $[\eta]$ of pure samples and samples cured for 1, 3, or 5 days were measured. Note that the curing took place below the melting temperature $\left(280^{\circ} \mathrm{C}\right.$ from the manufacturer), so that a solid-state cure was applied in this study. Figure 1 displays the viscosity-average molecular weights, which were calculated using the Mark-Houwink-Sakurada (MHS) equation. As-received PPS showed a viscosity-average molecular weight of $\sim 28,000 \mathrm{~g} / \mathrm{mol}$. The 1 day-cured sample revealed a significant increase in the viscosity-average molecular weight $(\sim 40,000 \mathrm{~g} / \mathrm{mol})$, which increased up to $\sim 58,000 \mathrm{~g} / \mathrm{mol}$ with a further increase of curing time ( 5 days). Thus, as expected, the thermal curing led to an increase of molecular weight. It is known that PPS has three different types of chain structure, linear, branched, and cross-linked, depending on the conditions of polymerization and thermal treatment [10]. The cross-linking structure in cured PPS has been investigated; it involves chain extension, thermal cross-linking, and oxidative cross-linking (Scheme 1) [10]. In our system, it is evident that a cross-linking structure was formed by thermal curing in the presence of oxygen.

\subsection{Non-Isothermal Crystallization Behavior}

The crystallization behavior of pure and cured PPS was investigated using non-isothermal DSC (Figure 2). In the

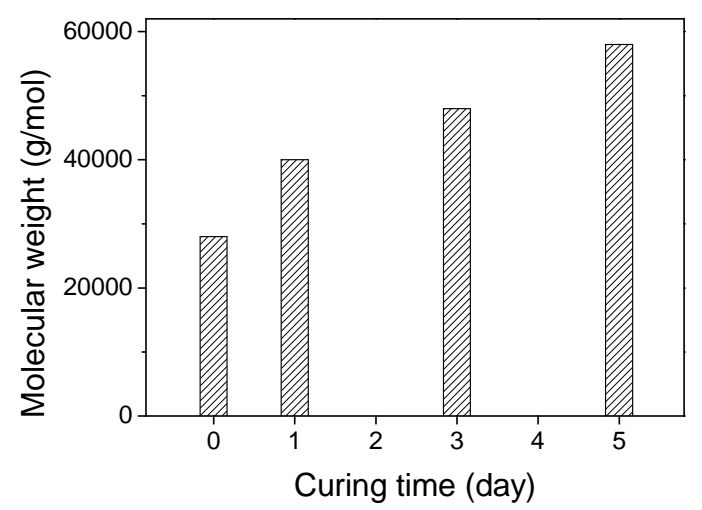

Figure 1. Viscosity-average molecular weights of pure PPS and samples cured for up to 5 days.

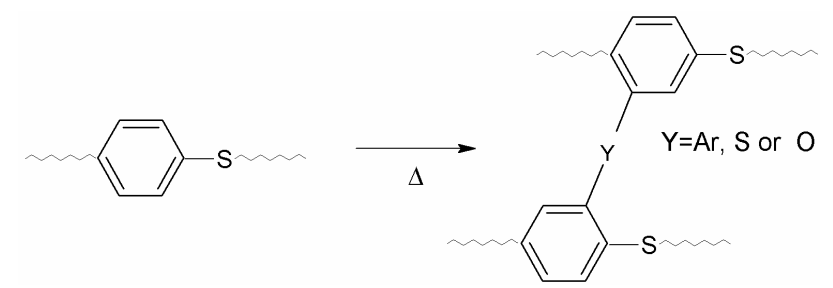

Scheme 1. Crosslinking mechanism of PPS during the curing process. 

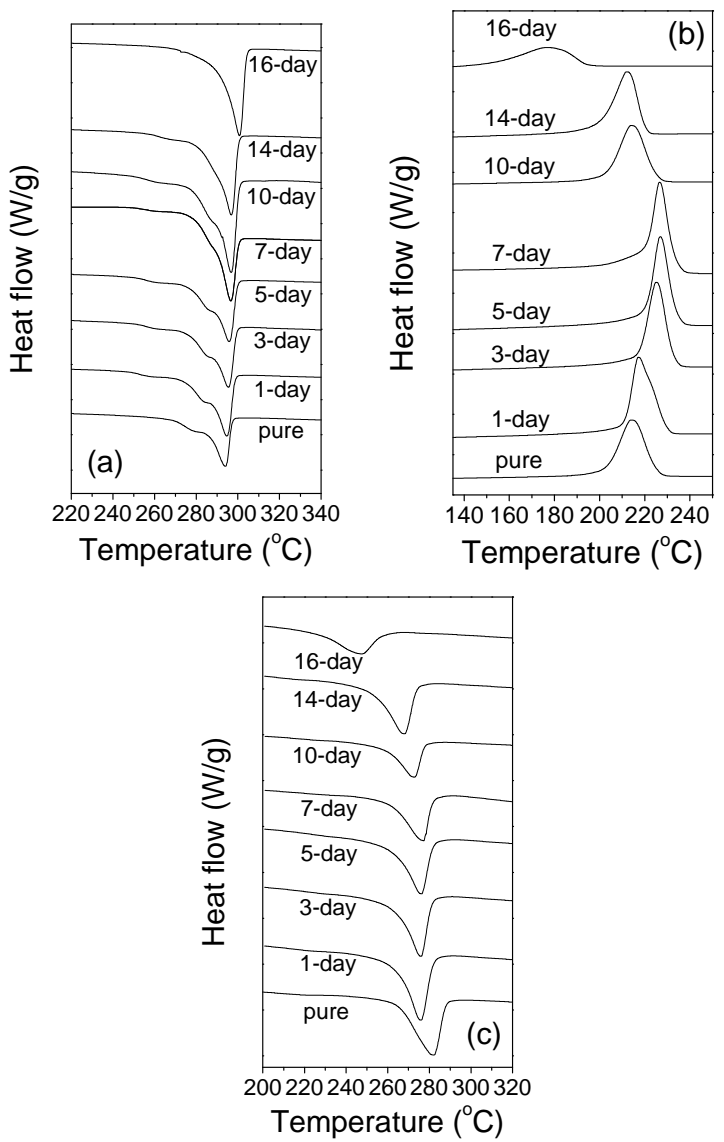

Figure 2. DSC thermograms of pure PPS and cured samples in (a) the first heating, (b) the first cooling, and (c) the second heating scan at a rate of $10^{\circ} \mathrm{C} / \mathrm{min}$.

first heating scan curve in Figure 2(a), pure PPS showed a shoulder at $\sim 280^{\circ} \mathrm{C}$ and the main melting temperature (Tm) with a heating rate of $10^{\circ} \mathrm{C} / \mathrm{min}$ was found to be at $294.0^{\circ} \mathrm{C}$. A significant change of $T_{m}$ was not observed for the 1 day cured PPS $\left(294.7^{\circ} \mathrm{C}\right)$. However, the shoulder shifted to $\sim 283^{\circ} \mathrm{C}$. It is interesting that another weak shoulder, at $\sim 260^{\circ} \mathrm{C}$, was observed only for the cured PPS samples; it could be the result of re-crystallization during solid-state curing in the oven at $250^{\circ} \mathrm{C}$. This shoulder and the main $T_{m}$ did not change for PPS samples cured for up to 14 days. The sample cured for 16 days showed $T_{m}$ of $300.7^{\circ} \mathrm{C}$ without any shoulder.

The PPS samples were held at $350^{\circ} \mathrm{C}$ for 10 min after the first heating scan to remove the prior thermal history and then slowly cooled at $10^{\circ} \mathrm{C} / \mathrm{min}$. In the first cooling, the crystallization temperature $\left(T_{c}\right)$ of pure PPS was $213.9^{\circ} \mathrm{C}$. There was a significant increase of $T_{c}$ for the 1 day cured sample $\left(224.9^{\circ} \mathrm{C}\right)$, and then a continuous further increase for samples cured for up to 7 days $\left(228.8^{\circ} \mathrm{C}\right)$. It is interesting to note that the further curing resulted in a decrease of crystallization temperature with the 16 days cured sample showing a $T_{c}$ of $177.3^{\circ} \mathrm{C}$. It is likely that the curing induced cross-linking structure led to a higher $T_{c}$ in the system because cross-linking structure acted as a nucleating agent. However, the further increase of curing time beyond 7 days caused the cross-linking structure to become dominant, which would hinder the formation of a crystalline structure.

Inoue and Suzuki described the effects of the crosslinking of ethylene-propylene-diene terpolymer (EPDM) particles on the crystallization of the polypropylene (PP) matrix [11]. The cross-linked EPDM/PP composites showed higher crystallization temperatures for the PP than occurred in the uncross-linked EPDM/PP composites, indicating that cross-linked EPDM played the role of a nucleating agent. More interestingly, a further increase in cross-linked EPDM content led to a decrease in the crystallization temperature of PP. We suggest that the cross-linking of PPS similarly acted as nucleating agents to change the crystallization behaviors of uncross-linked PPS.

The second heating scans were also obtained to investigate the melting behavior after the first controlled cooling in DSC because the first heating scans reflect the thermal history experienced during the thermal curing and initial processing. The second heating scans are presented in Figure 2(c), and the measured transition temperatures $\left(T_{m}\right)$ and heats of fusion $\left(\Delta H_{f}\right)$ are summarized in Table 1. In contrast to the first heating scans, only one melting peak was observed with all samples, which is evidence that the first melting peaks reflected the thermal history including the processing and curing. The melting peak in the second heating scan for pure PPS was found to be $282.2^{\circ} \mathrm{C}$. The 1 day cured sample showed a melting peak of $276.0^{\circ} \mathrm{C}, 6.2^{\circ} \mathrm{C}$ lower than that of pure PPS, and there was no significant difference of $T_{m}$ in the second heating scans up to the 7 days curing sample. However, the values decreased with a further increase of curing time. From the second heating scans, the crystallinities of

Table 1. Transition temperatures (in the $1^{\text {st }}$ heating, $1^{\text {st }}$ cooling, and $2^{\text {nd }}$ heating) and heat of fusion of pure PPS and cured samples in the second heating scans at a cooling rate of $10^{\circ} \mathrm{C} / \mathrm{min}$ and a heating rate of $10^{\circ} \mathrm{C} / \mathrm{min}$.

\begin{tabular}{ccccc}
\hline curing time & $\begin{array}{c}T_{m} \\
\left({ }^{\circ} \mathrm{C}\right)\left(1^{\mathrm{st}}\right)\end{array}$ & $\begin{array}{c}T_{c} \\
\left({ }^{\circ} \mathrm{C}\right)\end{array}$ & $\begin{array}{c}T_{m} \\
\left({ }^{\circ} \mathrm{C}\right)\left(2^{\text {nd }}\right)\end{array}$ & $\begin{array}{c}\Delta H_{f} \\
(\mathrm{~J} / \mathrm{g})\end{array}$ \\
\hline pure PPS & 294.0 & 213.9 & 282.2 & 32.9 \\
1 day & 294.7 & 224.9 & 276.0 & 27.3 \\
3 day & 295.5 & 226.9 & 276.0 & 24.7 \\
5 day & 295.9 & 227.2 & 276.2 & 22.8 \\
7 day & 296.7 & 228.8 & 277.4 & 21.7 \\
10 day & 296.7 & 220.7 & 272.3 & 21.3 \\
14 day & 296.9 & 212.3 & 268.1 & 21.1 \\
16 day & 300.7 & 177.3 & 247.4 & 14.6 \\
\hline
\end{tabular}


the samples were determined by dividing $\Delta H_{f}$ of crystallization by the $\Delta H_{f}^{o}$ value of $80.4 \mathrm{~J} / \mathrm{g}$ for PPS [12]; the values were found to be $40.9 \%, 34.0 \%, 28.4 \%, 21.3 \%$, and $14.6 \%$ for pure PPS and samples cured for $1,5,10$, and 16 days, respectively. It is evident that the crystallinity decreased as the curing time increased, presumably as a result of the cross-linking structure.

The non-isothermal crystallization kinetics of pure PPS and the cured samples were analyzed. The relative degree of crystallinity, $X$, at crystallization time $t$ can be obtained by the following equation:

$$
X=\frac{\int_{T_{o}}^{T}\left(\frac{\mathrm{d} H_{c}}{\mathrm{~d} T}\right) \mathrm{d} T}{\int_{T_{o}}^{T_{e}}\left(\frac{\mathrm{d} H_{c}}{\mathrm{~d} T}\right) \mathrm{d} T}
$$

where $T_{o}$ and $T_{e}$ are the onset and end crystallization temperatures, respectively, and $\mathrm{d} H_{c} / \mathrm{d} T$ is the heat flow rate. In non-isothermal crystallization, the time $t$ is related with the temperature $T$ as follows [13,14]:

$$
t=\frac{T_{o}-T}{\phi}
$$

where $T$ is the temperature at time $t, T_{o}$ is the temperature at which the crystallization begins $(t=0)$ and $\varphi$ is the cooling rate. Using the above two equations, the $X$ vs. $t$ plots of pure PPS and the cured samples in Figure 2(b) are shown in Figure 3. The half-crystallization times $\left(t_{1 / 2}\right)$ calculated from the $X$ vs. $t$ plots such as those in Figure 3 are summarized in Table 2. It was apparent for the pure samples and those cured for up to 7 days that a higher curing time resulted in less time being needed to reach a given relative degree of crystallinity, indicating a faster crystallization process. However, a further increase of curing time decreased $t_{1 / 2}$. From these results, it is noteworthy that even though thermally induced crosslinking led to a faster crystallization, excessive crosslink-ing hindered the crystallization, as was observed in the first cooling thermograms (Figure 2(b)).

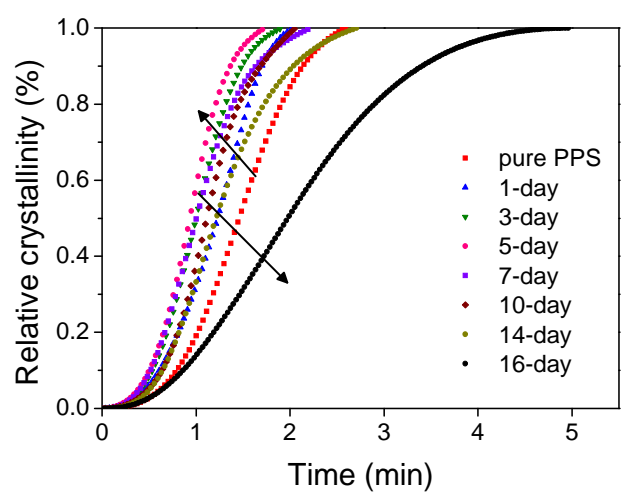

Figure 3. Relative crystallinity with time for non-isothermal crystallization of pure PPS and cured samples at a cooling rate of $10^{\circ} \mathrm{C} / \mathrm{min}$.
Table 2. The half-time of crystallization $\left(t_{1 / 2}\right)$ of pure PPS and cured samples at a cooling rate of $10^{\circ} \mathrm{C} / \mathrm{min}$.

\begin{tabular}{ccccccccc}
\hline $\begin{array}{c}\text { curing time } \\
\text { (day) }\end{array}$ & pure & 1 & 3 & 5 & 7 & 10 & 14 & 16 \\
\hline$t_{1 / 2}(\min )$ & 1.46 & 1.23 & 1.00 & 0.93 & 1.01 & 1.11 & 1.22 & 1.97 \\
\hline
\end{tabular}

\subsection{Polarized Optical Microscopy}

The crystalline morphologies of pure and cured PPS were observed using polarized optical microscopy (POM). To mimic the thermal history of the non-isothermal study in DSC, the samples were loaded on a hot stage and heated up to $350^{\circ} \mathrm{C}$ at a rate of $10^{\circ} \mathrm{C} / \mathrm{min}$ before being held at $350^{\circ} \mathrm{C}$ for $10 \mathrm{~min}$. Subsequently, the samples were cooled down to $50^{\circ} \mathrm{C}$ at a rate of $10^{\circ} \mathrm{C} / \mathrm{min}$, and the crystalline morphologies of the samples observed. The pure PPS (Figure 4(a)) showed spherulites whose size was 40 - 50 $\mu \mathrm{m}$. However, the $1-5$ days cured samples did not show clear spherulites. Instead, a large number of small crystals were observed (Figures 4(b)-(d)). It was reported that cross-linked EPDM particles acting as nucleating agents resulted in a decrease in the dimensions of PP spherulites [11]. The POM results for our system confirmed that cross-linked PPS induced by thermal curing also acted as a nucleating agent to decrease the crystalline size of PPS.

\section{Conclusion}

Commercial PPS was thermally cured, resulting in an increase of its molecular weight due to cross-linking as compared to the original sample; the viscosity-average molecular weight of samples cured for 5 days was $\sim 58,000$ $\mathrm{g} / \mathrm{mol}$. The crystallization temperature $\left(T_{c}\right)$ of pure PPS was found to be $213.9^{\circ} \mathrm{C}$ by non-isothermal DSC studies. The values of $T_{c}$ increased monotonously for samples cured for up to 7 days $\left(228.8^{\circ} \mathrm{C}\right)$, but a further increase in curing time up to 16 days led to a decrease of $T_{c}$ down to $177.3^{\circ} \mathrm{C}$. In addition, the change of the half-crystallization time $\left(t_{1 / 2}\right)$ was similar to that of the crystallization temperature. Pure PPS, and samples cured for 7 days and 16 days, showed half-crystallization times of 1.46, 1.01, and $1.97 \mathrm{~min}$, respectively. Thus, the cross-linking of PPS affected the crystallization behaviors significantly; a certain amount of cross-linking structure acted as a nucleation agent, but excessive cross-linked hindered the crystallization. Crystalline morphologies observed by polarized optical microscopy suggested that thermal curing for as little as 1 day contributed to the formation of smaller size crystalline structures, that the larger spherulites were not observed for pure PPS.

\section{Acknowledgements}

This work was supported by a grant from Korea Institute 


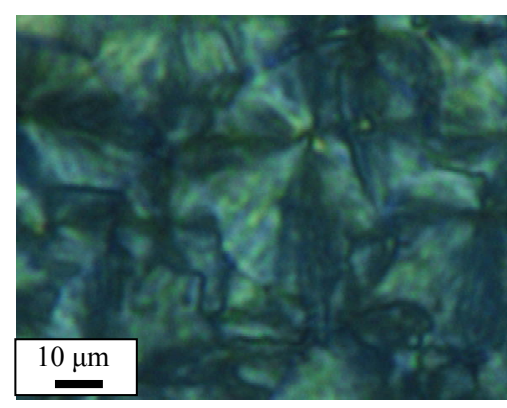

(a)

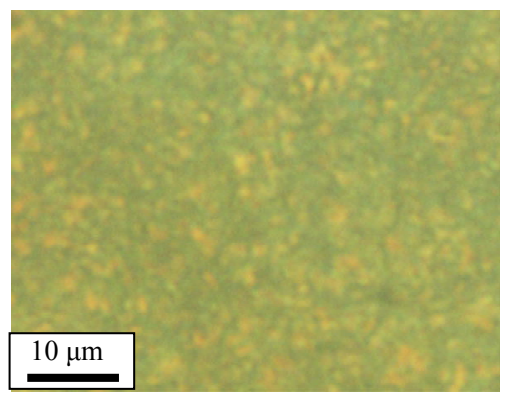

(a)

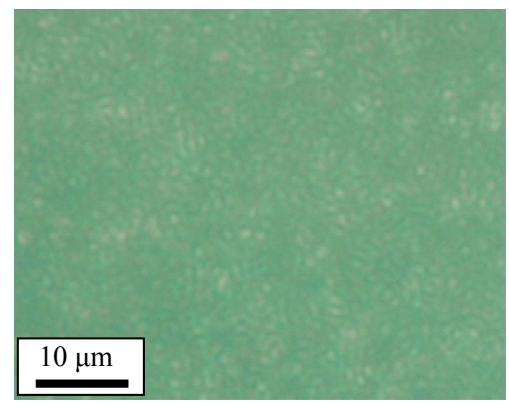

(b)

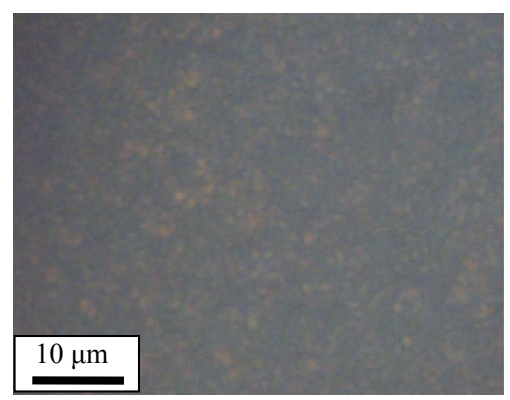

(b)

Figure 4. Polarized optical micrographs of (a) pure PPS, and samples cured for (b) 1 day, (c) 3 days, and (d) 5 days.

of Science and Technology Institutional program and the Fundamental R\&D Program for Core Technology of Materials funded by the Ministry of Knowledge Economy, Republic of Korea.

\section{REFERENCES}

[1] J. K. Fink, "5-Poly(phenylene sulfide)," In: J. K. Fink, Ed., High Performance Polymers, William Andrew Inc., Burlington, 2008, pp. 175-207. doi:10.1016/B978-081551580-7.50006-7

[2] J. T. Edmond and H. W. Hill Jr., "Production of Polymers from Aromatic Compounds," US Patent 3354129, 1967.

[3] L. C. Lopez and G. L. Wilkes, "Poly( $p$-Phenylene Sulfide) -An Overview of an Important Engineering Thermoplastic," Journal of Macromolecular Science Part C: Polymer Reviews, Vol. 29, No. 1, 1989, pp. 83-151. doi:10.1080/07366578908055165

[4] H. W. Hill Jr. and D. G. Brady, "High Performance Polymers and Composites," J. I. Kroschwitz, Ed., John Wiley \& Sons, New York, 1991, p. 551.

[5] P. Cebe, "Review of Recent Developments in Poly(phenylene Sulphide)," Polymer \& Polymer Composites, Vol. 3, 1995 , p. 239.

[6] H. W. Hill Jr. and D. G. Brady, "Properties, Environmental Stability, and molding Characteristics of Polyphenylene Sulfide," Polymer Engineering \& Science, Vol. 16, No. 12, 1976, pp. 831-835. doi:10.1002/pen.760161211

[7] D. G. Brady, "The Crystallinity of Poly(phenylene sulfide) and Its Effect on Polymer Properties," Journal of Applied Polymer Science, Vol. 20, No. 9, 1976, pp. 2541-2551. doi:10.1002/app.1976.070200921
[8] C. M. Ma, L. Hsiue, W. Wu and W. Liu, "Rheological and Morphological Properties of Thermal-Aged Poly(phenylene Sulfide) Resin," Journal of Applied Polymer Science, Vol. 39, No. 6, 1990, pp. 1399-1415. doi:10.1002/app.1990.070390615

[9] C. J. Stacy, "Molecular Weight Distribution of Polyphenylene Sulfide by High Temperature Gel Permeation Chromatography," Journal of Applied Polymer Science, Vol. 32, No. 3, 1986, pp. 3959-3969. doi:10.1002/app.1986.070320314

[10] R. T. Hawkins, "Chemistry of the Cure of Poly(p-phenylene Sulfide)," Macromolecules, Vol. 9, No. 2, 1976, pp. 189-194. doi:10.1021/ma60050a001

[11] T. Inoue and T. Suzuki, "Selective Crosslinking Reaction in Polymer Blends. III. The Effects of the Crosslinking of Dispersed EPDM Particles on the Impact Behavior of PP/EPDM Blends," Journal of Applied Polymer Science, Vol. 56, No. 9, 1995, pp. 1113-1125. doi:10.1002/app.1995.070560911

[12] D. G. Brady, "The Crystallinity of Poly(phenylene Sulfide) and Its Effect on Polymer Properties," Journal of Applied Polymer Science, Vol. 20, No. 9, 1976, pp. 25412551. doi:10.1002/app.1976.070200921

[13] P. Cebe, "Non-Isothermal Crystallization of Poly(ether Etherketone) Aromatic Polymer Composite," Polymer Composites, Vol. 9, No. 4, 1988, pp. 271-279. doi: $10.1002 /$ pc. 750090405

[14] C. R. Herrero and J. L. Acosta, "Effect of Poly(epichlorhydrin) on the Crystallization and Compatibility Behavior of Poly(ethylene oxide)/Polyphosphazene Blends," Polymer Journal, Vol. 26, 1994, pp. 786796. doi:10.1295/polymj.26.786 